\title{
Manganese-Catalyzed Asymmetric Hydrogenation of Quinolines Enabled by $\pi-\pi$ Interaction
}

\author{
Chenguang Liu, ${ }^{[a]}$ Mingyang Wang, ${ }^{[a]}$ Shihan Liu, ${ }^{[c]}$ Yujie Wang, ${ }^{[a]}$ Yong Peng, ${ }^{[a]}$ Yu Lan *b], ${ }^{[c]}$ and \\ Qiang Liu*[a]
}
[a] C. Liu, M. Wang, Y. Wang, Y. Peng and Prof. Dr. Q. Liu
Center of Basic Molecular Science (CBMS), Department of Chemistry, Tsinghua University
Beijing 100084, China
E-mail: qiang_liu@mail.tsinghua.edu.cn.
[b] Prof. Dr. Y. Lan*
Institute of Green Catalysis, College of Chemistry, Zhengzhou University
Zhengzhou, Henan 450001, China
E-mail: lanyu@cqu.edu.cn.
[c] S. Liu and Prof. Dr. Y. Lan
Chongqing Key Laboratory of Theoretical and Computational Chemistry, School of Chemistry and Chemical Engineering, Chongqing University
Chongqing 400030, China

\begin{abstract}
The first example of non-noble metal-catalyzed asymmetric hydrogenation of aromatic $\mathrm{N}$-heterocycles is reported. A new chiral pincer manganese catalyst showed outstanding catalytic activity in the asymmetric hydrogenation of a wide range of quinolines, affording high yields and excellent enantioselectivities (up to $97 \%$ ee). A turnover number of 3840 was reached at a low catalyst loading $(S / C=4000)$, which was competitive with the activity of most effective noble metal catalysts for this reaction. The precise regulation of the enantioselectivity were ensured by a $\pi-\pi$ interaction.
\end{abstract}

Optically active 1,2,3,4-tetrahydroquinolines(THQs), as an important structural motif, widely found in bioactive molecules and natural products. ${ }^{[1]}$ Numerous methods for constructing these chiral skeletons have been explored and reported. ${ }^{[2]}$ Significantly, the direct asymmetric hydrogenation $(\mathrm{AH})$ of quinolines remains one of the most efficient approaches to producing these compounds with high enantioselectivity. ${ }^{[3]}$ With the development

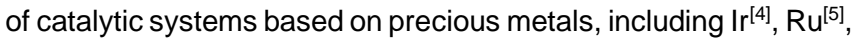
$\mathrm{Rh}^{[6]}$, and $\mathrm{Pd}{ }^{[7]}$, both the efficiency and substrate scope of the $\mathrm{AH}$ of quinolines have been greatly improved (Scheme 1, A). Specifically, iridium catalysts containing chiral bisphosphine ligands have proven to be effective for the hydrogenation of quinolines activated by iodine since the pioneering work of Zhou in 2003. ${ }^{[4 a]}$ Furthermore, Fan, Chan, and coworkers have shown cationic complex Ru(OTf)(TsDPEN)-( $\eta^{6}$-cymene) to be a state-ofthe-art catalyst for this transformation, affording outstanding enantioselectivity and a broad substrate scope. ${ }^{[5 a, 5 c]}$ In addition to transition metal catalysts, frustrated Lewis pairs (FLPs) are also powerful catalysts for the $\mathrm{AH}$ of quinolines. ${ }^{[8]}$ Although the above two catalytic systems remain unsurpassed at present, they still have some shortcomings. For precious metal catalysts, issues of high cost, uncertain supply, and toxicity concerns remain unsolved. Meanwhile for FLP catalysis, preparation of chiral bisborane catalysts are usually complicated and a higher catalyst loading is required compared with transition metal catalysis. Such limitations may restrict the wide applications of these catalytic systems on a large scale. Therefore, the development of more sustainable and practical catalysts for the $\mathrm{AH}$ of quinolines remains a highly desirable, but challenging task.

To achieve such a goal, the application of non-noble metals, such as iron ${ }^{[9]}$, cobalt ${ }^{[9 d, 9 f, 10]}$ and nickel ${ }^{[11]}$, to the development of new $\mathrm{AH}$ catalysts is a feasible strategy ${ }^{[12]}$. Accordingly, manganese, which is the third most abundant transition metal on earth and exhibits low toxicity, is another ideal choice. ${ }^{[13]} \mathrm{Mn}$ catalyzed hydrogenation reactions have seen significant progress $^{[14]}$ since the seminal work of Beller and co-workers in $2016 .{ }^{[15]}$ In particular, Mn-catalyzed $\mathrm{AH}$ of ketone has also been reported $^{[16]}$, among which Ding, Han and co-workers developed a highly efficient chiral manganese catalyst for this transformation. ${ }^{[16 c, 16 \mathrm{~d}]}$ This demonstrates the great potential of Mn-based catalysts in $\mathrm{AH}^{\left[{ }^{[17]}\right.}$ However, no example of manganese-catalyzed $\mathrm{AH}$ of unsaturated compounds other than ketones has been reported to date.

A) Known catalytic asymmetric hydrogenation $(\mathrm{AH})$ of quinolines

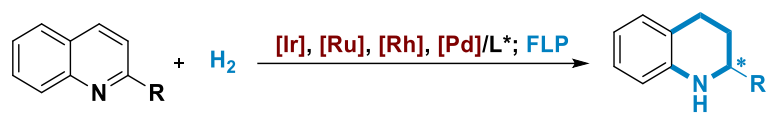

B) This work: Manganese-Catalyzed AH of Quinolines

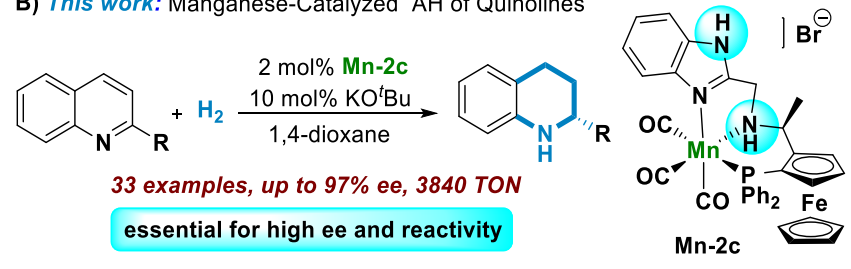

Scheme 1. Asymmetric hydrogenation of 2-substituted quinolines.

Following our continued pursuit of Mn-catalyzed (de)hydrogenation reactions ${ }^{[18]}$, herein we disclosed an enantioselective manganese-catalyzed hydrogenation of quinolines with up to $97 \%$ ee and a maximum turnover number (TON) of 3840. The high reactivity and effective enantioselectivity control of this chiral catalyst are enabled by the dual "N-H effect" of a newly designed chiral NNP tridentate ligand (Scheme 1, B). To our knowledge, this is the first example of asymmetric hydrogenation of aromatic $\mathrm{N}$-heterocycle catalyzed by first-row earth-abundant transition metals.

In a recent study, we found that an imidazole based NNP-Mn pincer catalyst performed with high efficiency in the hydrogenation of $N$-heterocycles owing to the enhanced electrondonating ability and low steric hindrance of the imidazole group ${ }^{[18 c, 19]}$ Inspired by this ligand effect, we aimed to design an imidazole-based chiral NNP-tridentate ligand for the Mncatalyzed $\mathrm{AH}$ of quinolines. Coincidentally, Zhong and co-workers recently developed in-situ formed $\mathrm{Mn}(\mathrm{I})$ catalysts containing imidazole-based chiral NNP tridentate ligands, which enabled the enantioselective hydrogenation of unsymmetrical benzophenones. ${ }^{[20]}$ In this case, the use of ligand ${ }^{\text {L }}$ 1a with a 
bulky substituent on the $\mathrm{N}$ atom of the benzo[d]imidazole segment was essential for achieving high enantioselectivity. Initially, we attempted to use ${ }^{S} \mathbf{L 1 a}$ for the hydrogenation of 2-methylquinoline $3 \mathbf{a}$ in the presence of $\mathrm{Mn}(\mathrm{CO})_{5} \mathrm{Br}$ as the catalyst precursor (Scheme 2). However, low conversion and moderate enantioselectivity were observed. We hypothesized that this sterically hindered ligand prevented the coordination of bulky substrates to the metal center and reduced the reactivity of the $\mathrm{Mn}-\mathrm{H}$ species in the hydrogen transfer step.

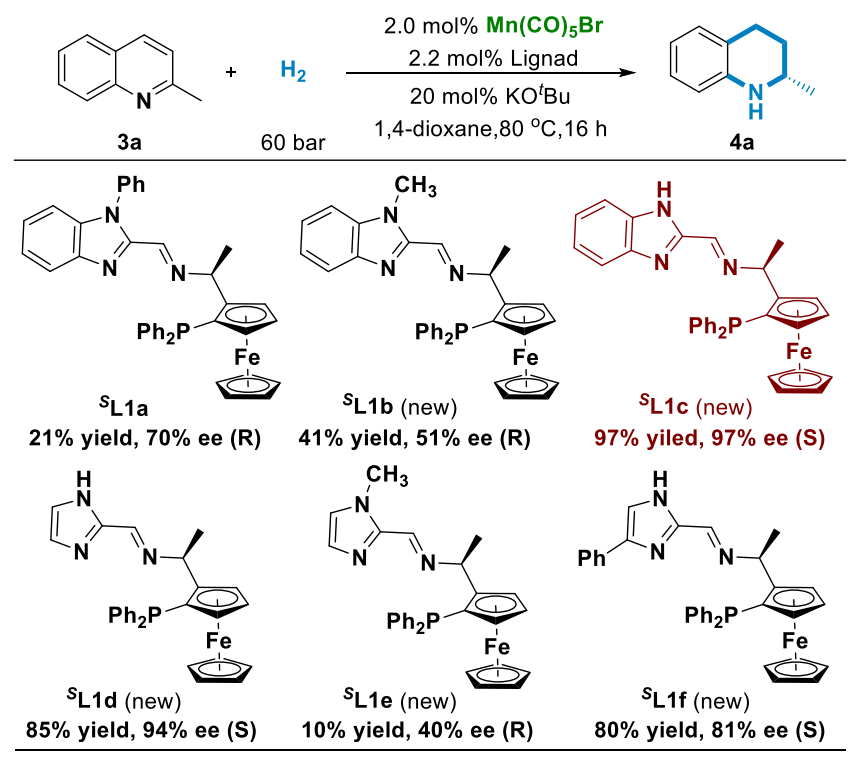

Scheme 2. Ligand Screening. Reaction conditions: $3 \mathbf{a}(0.25 \mathrm{mmol}), \mathrm{Mn}(\mathrm{CO})_{5} \mathrm{Br}$ (2.0 mol\%), ${ }^{s}$ L1 (2.2 mol\%), and KO'Bu (20 mol\%) in 1,4-dioxane $(0.5 \mathrm{~mL})$ at $80{ }^{\circ} \mathrm{C}$ for $16 \mathrm{~h}$. Conversions (\%) and enantioselectivities (\%ee) were determined by GC and chiral-phase HPLC.

This unsatisfactory result reminded us of our previous work, in which mechanistic studies showed that both the steric and electronic effects of the heterocyclic segment in the ligand are important for reactivity. ${ }^{[18 c]}$ Accordingly, we envisaged controlling the reactivity and enantioselectivity by regulating the structures of heterocycle motifs in the ligands. Improved yield and reduced enantioselectivity ( $45 \%$ conv, $51 \%$ ee) were obtained by changing the substituent on the benzo[d]imidazole $\mathrm{N}$-atom from a phenyl to methyl group ( $\left.{ }^{s} \mathbf{L} \mathbf{1 b}\right)$. Notably, $\mathbf{3 a}$ was almost quantitatively converted into product $\mathbf{4 a}$ with excellent reversed enantioselectivity ( $97 \%$ ee) by further changing the methyl group to an $\mathrm{H}$ atom $\left({ }^{S} \mathbf{L} 1 \mathrm{c}\right)$. These results showed that reduced steric hindrance on the $\mathrm{N}$-atom of the benzo[d]imidazol group was highly important for increasing both reactivity and enantioselectivity. Furthermore, imidazole-based NNP tridentate ligands were synthesized to confirm this conjecture. Compared with the methyl-substituted ligand $\left({ }^{(} \mathbf{L} 1 \mathbf{e}\right)$, the $\mathrm{NH}$-imidazole-based ligand $\left({ }^{\mathrm{S}} \mathbf{L} \mathbf{d d}\right)$ also furnished 4a with a substantially increased yield and fully reversed configuration ( $88 \%$ conv, $94 \%$ ee). This comparison again highlights the essential effect of the less hindered NH unit. Monoaryl substituted imidazole (mixture of 4/5-tautomers ${ }^{[21]}$ ) ligand ${ }^{S}$ L1f was also synthesized to further investigate the effect of the substituent on the imidazole ring, while a decreased enantioselectivity was observed for the hydrogenation of $\mathbf{3 a}$. Other reaction parameters were also optimized to improve the reaction efficiency (see Supporting Information for more details).
The best result was achieved using $\mathrm{Mn}(\mathrm{CO})_{5} \mathrm{Br}(2.0 \mathrm{~mol} \%)$, ${ }^{S} \mathrm{L1c}$ (2.2 mol\%), KO'Bu (10 mol\%), and 1,4-dioxane as solvent at 80 ${ }^{\circ} \mathrm{C}$.

To elucidate the structure of in-situ formed active catalyst, we synthesized the NNP-pincer manganese complex by reacting $\mathrm{Mn}(\mathrm{CO})_{5} \mathrm{Br}$ with saturated pincer ligand ' $\mathrm{L1c}$ ' (Scheme 3(a)). The catalytic activity of $\mathbf{M n - 2 c}$ was further evaluated in the $\mathrm{AH}$ of $\mathbf{3 a}$ for comparison with the performance of in-situ formed catalytic systems. A similar yield and enantioselectivity were obtained using well-defined catalyst $\mathbf{M n - 2 c}$ and the catalytic system formed in-situ from $\mathrm{Mn}(\mathrm{CO})_{5} \mathrm{Br}$ and ' $\mathbf{L} 1 \mathrm{c}^{\prime}$ (or ' $\mathrm{L} \mathbf{L 1 c}$ ). These results demonstrated that NNP-pincer manganese complex $\mathbf{M n - 2 c}$ was an active catalyst precursor.

(a)Preparation of NNP-pincer Mn complex

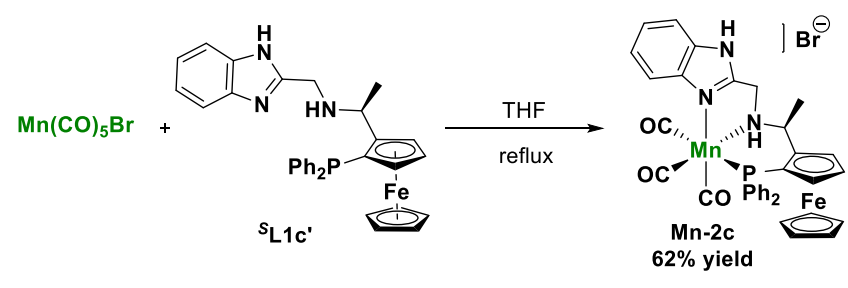

(b) Study of "N-H" effect on catalytic performance
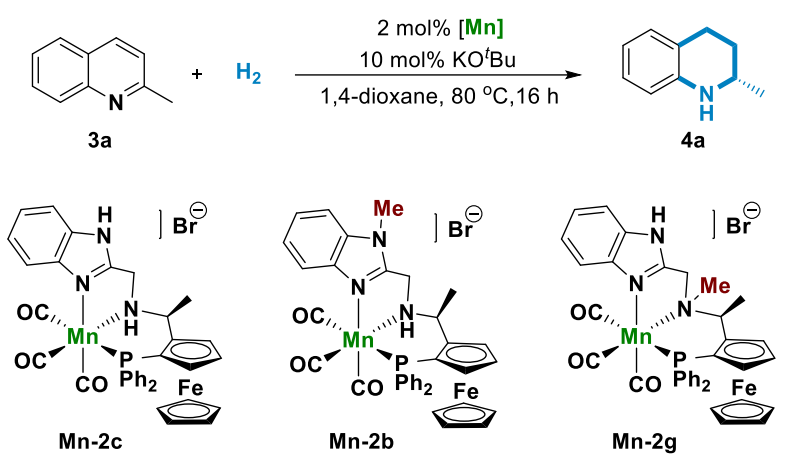

$98 \%$ yield, $97 \%$ ee (S)

$32 \%$ yield, $60 \%$ ee $(R)$

$<5 \%$ yield

Scheme 3. Synthesis and reactivity of pincer complexes Mn-2.

The NH moiety on pincer ligands can greatly impact the reactivity in catalytic hydrogenation via metal-ligand cooperation. ${ }^{[22]}$ To investigate the effect of two $\mathrm{NH}$ moieties on optimal catalyst $\mathbf{M n - 2 \mathbf { c }}$, two $\mathrm{N}$-methylated complexes, $\mathbf{M n - 2} \mathbf{b}$ and $\mathbf{M n - 2 g}$, were prepared and their catalytic activities were evaluated (Scheme 3(b)). A lower yield and ee value were observed for the $\mathrm{AH}$ of $\mathbf{3 a}$ using $\mathbf{M n - 2} \mathbf{b}$ as catalyst compared with the result using Mn-2c under the same reaction conditions. However, almost no conversion was observed when using complex $\mathbf{M n - 2} \mathbf{g}$ as catalyst. These results indicated the strong beneficial influence of cooperative $\mathrm{N}-\mathrm{H}$ functionality on this transformation. Specifically, the central $\mathrm{NH}$ group was crucial for reactivity via metal-ligand cooperation. Although the imidazole-NH motif also influenced the reactivity, it was more important for achieving high enantioselectivity owing to its very low steric hindrance. Density functional theory (DFT) calculations were conducted to understand the mechanism and origin of chirality in the $\mathrm{AH}$ of $\mathbf{3 a}$. $\mathrm{H}_{2}$ activation was regarded as the rate-determining step of the whole catalytic process, with an activation free energy of 20.5 $\mathrm{kcal} / \mathrm{mol}$ using Mn-2c as the catalyst (Scheme S4). This energy 
barrier was $2.0 \mathrm{kcal} / \mathrm{mol}$ lower than for the same process promoted by $\mathrm{Mn}-2 \mathrm{~b}$, benefiting from smaller steric hindrance on the imidazole ring. This result was in good accordance with the observed lower reactivity of $\mathbf{M n - 2} \mathbf{b}$ as catalyst. Following the $\mathrm{H}_{2}$ activation step, the reaction proceeds via 1,4 addition of the $\mathrm{Mn}$ $\mathrm{H}$ species to $3 \mathbf{a}$, which is both thermodynamically and kinetically favorable over the 1,2-addition reaction pathway (Schemes S5 and S8). Subsequently, the enamine intermediate undergoes a facile base-promoted isomerization to form an imine intermediate (Scheme S6), followed by enantio-determining hydrogenation of the imine to deliver the final product (Scheme S7).

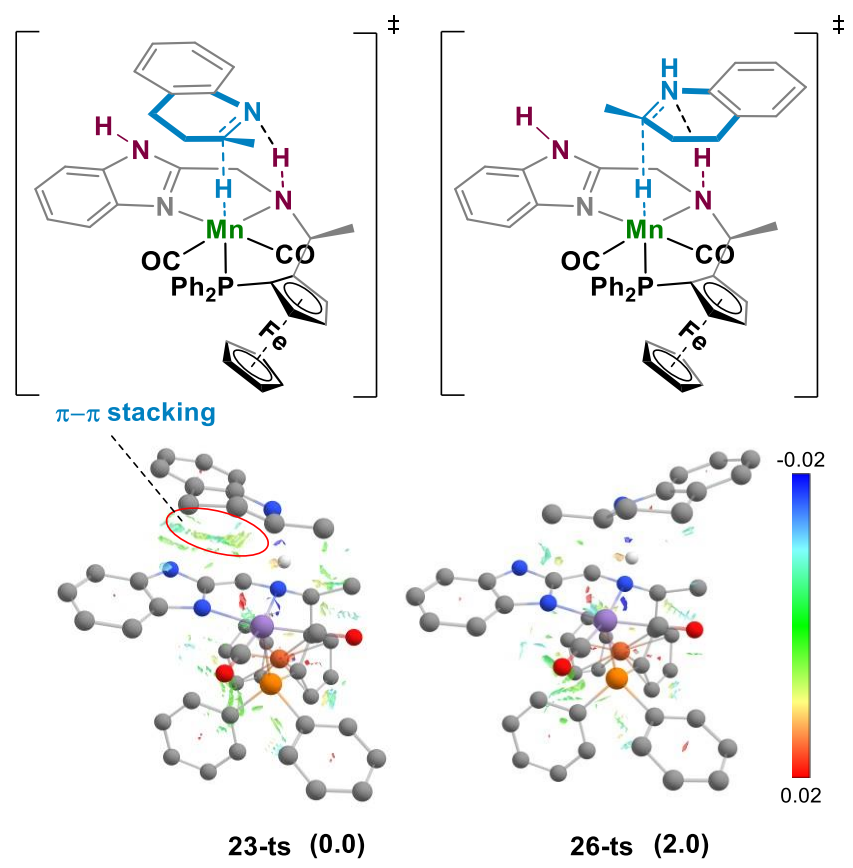

Figure 1. $\mathrm{NCl}$ analysis of 23-ts and 26-ts (blue: attraction; green: weak interaction; red: repulsion). Relative Gibbs free energies (in $\mathrm{kcal} / \mathrm{mol}$ ) are reported in parentheses.

Analysis of the noncovalent interactions ( $\mathrm{NCl}$ ) showed that 23-ts was calculated to be more stable than 26-ts by a free energy of $2.0 \mathrm{kcal} / \mathrm{mol}$, owing to the $\pi-\pi$ nonbonding interaction between the imidazole ring and $\mathrm{C}=\mathrm{N}$ double bond in 23-ts (Figure 1). This was in agreement with the experimental results. Therefore, the $S$-configured product was preferentially formed with excellent enantioselectivity. The $\mathrm{NH}$ unit of the imidazole motif in the ligand ensured an effective $\pi-\pi$ interaction owing to its small volume, playing a key role in enantio-induction.

With optimized reaction conditions in hand, the scope of 2substituted quinoline substrates was studied (Scheme 4). A wide range of substrate(3b-3h) with substituents on benzene ring were hydrogenated to the corresponding chiral 1,2,3,4-THQs (4b-4h) with ee values ranging from $91 \%$ to $97 \%$. Notably, other reducible functional groups, such as halogens (4b-4d), and carbon-carbon double(4g) and triple(4h) bonds, were all well tolerated. Various 2-benzyl substituted quinolines, bearing substituents with different electronic properties, were converted to the corresponding products (4i-4I) effectively in $82 \%-99 \%$ yields with $89 \%-97 \%$ ee values. This method was also proved to be applicable to the $\mathrm{AH}$ of other 2-substituted (n-pentyl, $n$-octyl, isopropyl, cyclohexyl, phenemyl and distal olefins) substrates
$(3 m-30,3 q-3 r, 3 t-3 u)$, providing the corresponding products with excellent yields and ee values (86-93\%).

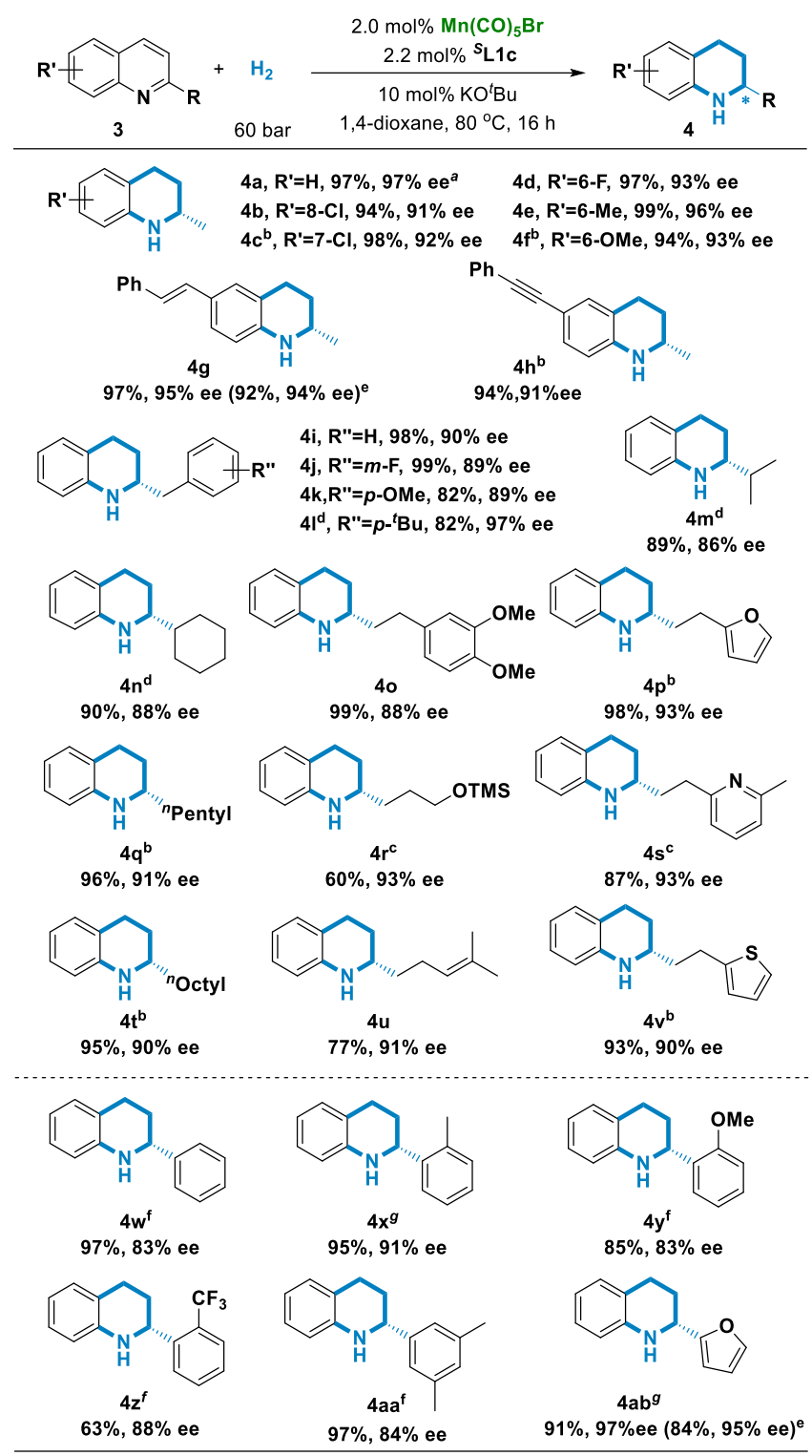

Scheme 4. Asymmetric hydrogenation of 2-substituted quinoline. Reaction conditions: 3 (0.25 mmol), $\mathrm{Mn}(\mathrm{CO})_{5} \mathrm{Br}(2.0 \mathrm{~mol} \%),{ }^{S} \mathrm{~L} 1 \mathrm{c}(2.2 \mathrm{~mol} \%)$, and $\mathrm{KO} \mathrm{Bu}^{\mathrm{B}}$ $(10 \mathrm{~mol} \%)$ in 1,4 -dioxane $(0.5 \mathrm{~mL})$ at $80^{\circ} \mathrm{C}$ for $16 \mathrm{~h}$. [a] The percentages shown are yields of isolated products and ee values in that order. [b] $20 \mathrm{~mol} \% \mathrm{KO} \mathrm{Bu}^{\mathrm{B}}$ was used. [c] $20 \mathrm{~mol} \% \mathrm{KO}^{\mathrm{t}} \mathrm{Bu}$ was used at $110^{\circ} \mathrm{C}$. [d] ${ }^{\mathrm{S}} \mathrm{L} 1 \mathrm{~d}(2.2 \mathrm{~mol} \%)$ and 20 mol\% KO'Bu were used at $110^{\circ} \mathrm{C}$. [e] Saturated ligands 'L1c' or 'L1d' (2.2 mol\%) was used. [f] ${ }^{S}$ L1f was used. [g] ${ }^{S}$ L1d was used.

Furthermore, substrates bearing other aromatic heterocycles (furan (3p), pyridine (3s), and thiophene (3v)) were also efficiently hydrogenated, affording $90 \%-93 \%$ ee values with the additional heterocycles untouched. Notably, chiral THQs $\mathbf{4 d}, \mathbf{4 o}$ and $\mathbf{4 q}$ were key intermediates for the synthesis of natural products (S)flumequine ${ }^{[23]}, \quad(+)$-angustrureine $e^{[24]}$ and (-)-cuspareine ${ }^{[24]}$, respectively. Various 2-aryl substituted quinolines were subsequently subjected to Mn-catalyzed $\mathrm{AH}$. A further ligand screening showed that ligand ${ }^{S} \mathbf{L} 1 \mathbf{f}$ gave the best results for these substrates (Scheme S1), with 63\%-97\% yields and $83 \%-97 \%$ ee values. Various substituents on the phenyl ring were well tolerated 
(4w-4aa). Notably, a heterocycle-substituted quinoline was also a suitable substrate for this transformation (4ab).

The hydrogenation products of bis(quinoline-2-yl)-methanes are synthetic precursors for chiral $\mathrm{N}$-heterocyclic carbene $(\mathrm{NHC})$ ligands ${ }^{[25]}$. This new catalytic system was applied to constructing such compounds containing two chiral centers (Scheme 5). The $\mathrm{AH}$ of various bis(quinoline-2-yl)-methanes bearing methyl, isopropyl and phenyl groups gave the desired products (6a-6d) with excellent diastereoselectivities and enantioselectivities (95\%-97\% ee). Subsequent treatment of $(\boldsymbol{R}, \boldsymbol{R})-\mathbf{6 c}$ with triethyl orthoformate and $\mathrm{NH}_{4} \mathrm{BF}_{4}$ afforded six-membered rigid chiral $\mathrm{NHC}$ ligand precursor $7 \mathrm{c}$ in $97 \%$ yield.

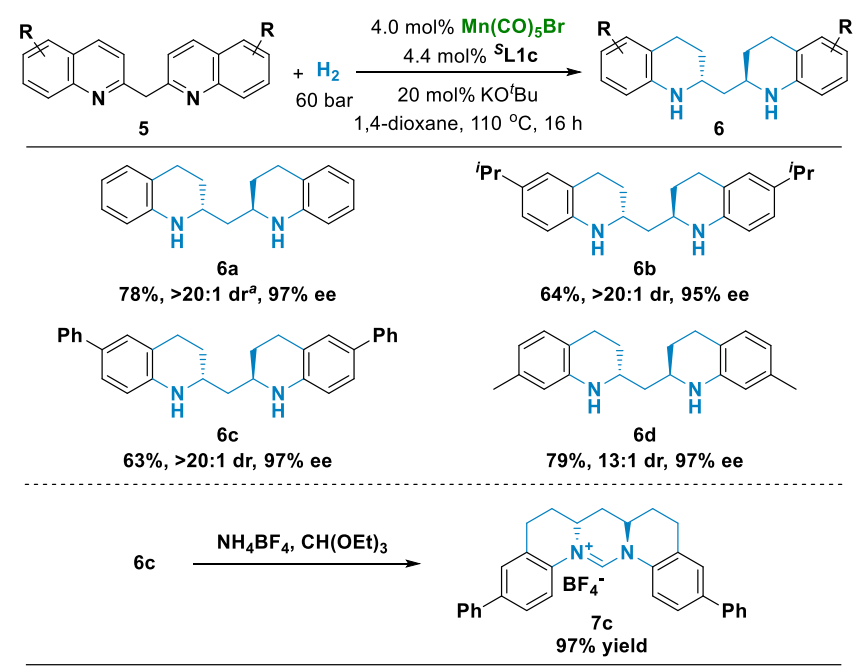

Scheme 5. Asymmetric hydrogenation of bis(quinolin-2-yl)methanes. Reaction conditions: 5 (0.25 mmol), $\mathrm{Mn}(\mathrm{CO})_{5} \mathrm{Br}(4.0 \mathrm{~mol} \%),{ }^{\text {s L } 1 \mathrm{c}}(4.4 \mathrm{~mol} \%)$, and $\mathrm{KO} \mathrm{Bu}^{\mathrm{B}}$ (20 mol\%) in 1,4-dioxane $(0.5 \mathrm{~mL})$ at $110^{\circ} \mathrm{C}$ for $16 \mathrm{~h}$. [a] Diastereoselectivities were determined by ${ }^{1} \mathrm{H}$ NMR analysis of crude products and chiral-phase HPLC.

To further evaluate the efficiency of this catalytic system, a gram-scale reaction was performed using 2-methylquinoline 3a as the model substrate with a catalyst loading of $0.025 \mathrm{~mol} \%$ (Scheme 6a). Excellent enantioselectivity was maintained in this transformation, with a TON of 3840 achieved. The synthetic utility of this Mn-catalyzed $\mathrm{AH}$ was demonstrated by the synthesis of a drug lead compound (Scheme $6 \mathrm{~b}$ ). The enantiomer of compound 10 has been reported as an effective $y$-secretase inhibitor for the treatment of Alzheimer's disease (AD). ${ }^{[26]}$ Synthesis of this molecule started with the $\mathrm{AH}$ of commercially available substrate 3ac, followed by sulfonylation to give sulfonamide $\mathbf{8}$. Deprotection of methyl group provided chiral alcohol $\mathbf{9}$, which was converted to final product 10 with retention of the enantioselectivity. ${ }^{[27]}$ This is the first example of the enantioselective synthesis of 10 via asymmetric catalysis, which is a more sustainable synthetic route compared with the reported chiral resolution protocol. ${ }^{[27]}$

In summary, we have developed the first non-noble metalcatalyzed asymmetric hydrogenation of aromatic $\mathrm{N}$-heterocycles, using a newly designed chiral manganese catalyst. This catalytic system was applicable to the asymmetric hydrogenation of 2substituted quinolines and bis(quinoline-2-yl)-methanes with excellent diastereoselectivities and enantioselectivities. Furthermore, a TON of 3840 was achieved, along with excellent yields and enantioselectivities, demonstrating the high efficiency of this newly designed chiral manganese catalyst. A detailed mechanistic study of this catalytic system is under way in our lab.

(a) Gram-scale reaction under a high $\mathrm{S} / \mathrm{C}$ ratio

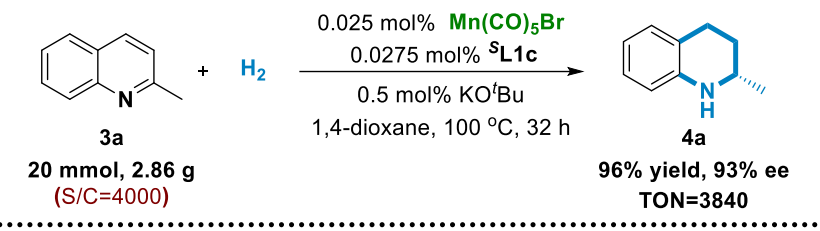

(b) Asymmetric synthesis of $\gamma$-Secretase inhibitor ${ }^{a}$<smiles>COCc1ccc2ccccc2n1</smiles>

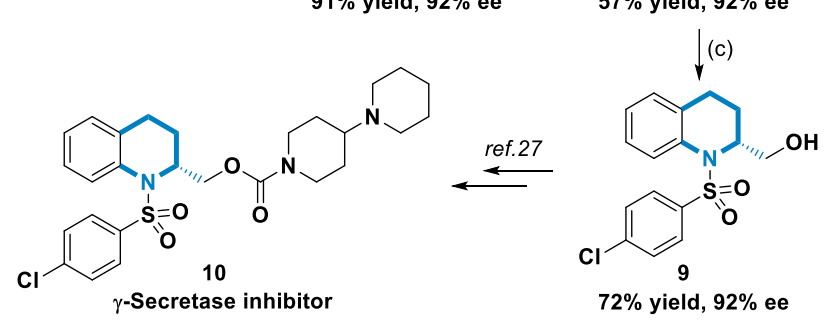

Scheme 6. Catalytic efficiency and synthetic application. [a] Reaction conditions: (a) 3ac $(8.8 \mathrm{mmol}), \mathrm{Mn}(\mathrm{CO})_{5} \mathrm{Br}(0.11 \mathrm{~mol} \%),{ }^{S} \mathrm{L1c}(0.12 \mathrm{~mol} \%)$ $\mathrm{KO}{ }^{\mathrm{B} u}(2.2 \mathrm{~mol} \%), 1,4$-dioxane $(1 \mathrm{~mL}), 80^{\circ} \mathrm{C}, \mathrm{H}_{2}(60 \mathrm{bar})$ for $16 \mathrm{~h}$. (b) $\mathrm{ArSO}_{2} \mathrm{Cl}$, $\mathrm{Et}_{3} \mathrm{~N}$, THF, reflux. (c) $\mathrm{BBr}_{3}, 15-$ crown-5, Nal, DCM, $-30^{\circ} \mathrm{C}$.

\section{Acknowledgements}

This project was supported by the National Natural Science Foundation of China ((21822106 and 91845107) and the Foundation of the Department of Education of Guangdong Province (2018KZDXM070 and 2019KZDXM052).

Keywords: Manganese $\cdot$ Asymmetric hydrogenation $\cdot \mathrm{NH}$ effect - $N$-heterocycles $\cdot$ Metal-ligand cooperation

[1] a) V. Sridharan, P. A. Suryavanshi, J. C. Menéndez, Chem. Rev. 2011 111, 7157-7259; b) I. Muthukrishnan, V. Sridharan, J. C. Menéndez, Chem. Rev. 2019, 119, 5057-5191.

[2] a) A. R. Katritzky, S. Rachwal, B. Rachwal, Tetrahedron. 1996, 52, 15031-15070; b) V. Kouznetsov, A. Palma, C. Ewert, A. Varlamov, J. Heterocycl. Chem. 1998, 35, 761-785; c) G. D. Muñoz, G. B. Dudley, Org. Prep. Proced. Int. 2015, 47, 179-206.

[3] a) D.-S. Wang, Q.-A. Chen, S.-M. Lu, Y.-G. Zhou, Chem. Rev. 2012, 112, 2557-2590; b) Y.-M. He, F.-T. Song, Q.-H. Fan, in Stereoselective Formation of Amines (Eds.: W. Li, X. Zhang), Springer,Berlin, Heidelberg, 2014, pp. 145-190; c) Z. X. Giustra, J. S. A. Ishibashi, S.-Y. Liu, Coord. Chem. Rev. 2016, 314, 134-181; d) Y.-E. Luo, Y.-M. He, Q.-H. Fan Chem. Rec. 2016, 16, 2697-2711; e) K. Mashima, K. Higashida, A limuro, H. Nagae, Y. Kita, Chem. Rec. 2016, 16, 2585-2598; f) M. P. Wiesenfeldt, Z. Nairoukh, T. Dalton, F. Glorius, Angew. Chem. Int. Ed. 2019, 58, 10460-10476.

[4] a) W.-B. Wang, S.-M. Lu, P.-Y. Yang, X.-W. Han, Y.-G. Zhou, J. Am Chem. Soc. 2003, 125, 10536-10537; b) L. Xu, K. H. Lam, J. Ji, J. Wu Q.-H. Fan, W.-H. Lo, A. S. C. Chan, Chem. Commun. 2005, 1390-1392; c) S.-M. Lu, Y.-Q. Wang, X.-W. Han, Y.-G. Zhou, Angew. Chem. Int. Ed. 2006, 45, 2260-2263; d) L. Qu, F. Y. Kwong, J. Wu, W. H. Lam, S. Chan, W.-Y. Yu, Y.-M. Li, R. Guo, Z. Zhou, A. S. C. Chan, J. Am. Chem. Soc 
2006, 128, 5955-5965; e) M. T. Reetz, X. Li, Chem. Commun. 2006 2159-2160; f) W.-J. Tang, S.-F. Zhu, L.-J. Xu, Q.-L. Zhou, Q.-H. Fan, H.F. Zhou, K. Lam, A. S. C. Chan, Chem. Commun. 2007, 613-615; g) X.B. Wang, Y.-G. Zhou, J. Org. Chem. 2008, 73, 5640-5642; h) H. Tadaoka D. Cartigny, T. Nagano, T. Gosavi, T. Ayad, J.-P. Genêt, T. Ohshima, V. Ratovelomanana-Vidal, K. Mashima, Chem. Eur. J. 2009, 15, 99909994; i) W.-J. Tang, J. Tan, L.-J. Xu, K.-H. Lam, Q.-H. Fan, A. S. C. Chan, Adv. Synth. Catal. 2010, 352, 1055-1062.

[5] a) H. Zhou, Z. Li, Z. Wang, T. Wang, L. Xu, Y. He, Q.-H. Fan, J. Pan, L. Gu, A. S. C. Chan, Angew. Chem. Int. Ed. 2008, 47, 8464-8467; b) Z.-J. Wang, H.-F. Zhou, T.-L. Wang, Y.-M. He, Q.-H. Fan, Green Chem. 2009 11, 767-769; c) T. Wang, L.-G. Zhuo, Z. Li, F. Chen, Z. Ding, Y. He, Q. H. Fan, J. Xiang, Z.-X. Yu, A. S. C. Chan, J. Am. Chem. Soc. 2011, 133 9878-9891; d) W. Ma, J. Zhang, C. Xu, F. Chen, Y.-M. He, Q.-H. Fan, Angew. Chem. Int. Ed. 2016, 55, 12891-12894; e) Y. Chen, Y.-M. He, S. Zhang, T. Miao, Q.-H. Fan, Angew. Chem. Int. Ed. 2019, 58, 3809-3813; f) Y. Chen, Y. Pan, Y.-M. He, Q.-H. Fan, Angew. Chem. Int. Ed. 2019, 58, 16831-16834.

[6] J. Wen, R. Tan, S. Liu, Q. Zhao, X. Zhang, Chem. Sci. 2016, 7, $3047-$ 3051.

[7] X.-F. Cai, W.-X. Huang, Z.-P. Chen, Y.-G. Zhou, Chem. Commun. 2014 $50,9588-9590$

[8] a) Z. Zhang, H. Du, Org. Lett. 2015, 17, 2816-2819; b) Z. Zhang, H. Du, Org. Lett. 2015, 17, 6266-6269; c) Z. Zhang, H. Du, Angew. Chem. Int Ed. 2015, 127, 633-636; d) X. Li, J.-J. Tian, N. Liu, X.-S. Tu, N.-N. Zeng X.-C. Wang, Angew. Chem. Int. Ed. 2019, 58, 4664-4668.

[9] a) R. H. Morris, Chem. Soc. Rev. 2009, 38, 2282-2291; b) W. Zuo, A. J. Lough, Y. F. Li, R. H. Morris, Science. 2013, 342, 1080; c) P. O. Lagaditis P. E. Sues, J. F. Sonnenberg, K. Y. Wan, A. J. Lough, R. H. Morris, J. Am. Chem. Soc. 2014, 136, 1367-1380; d) P. J. Chirik, Acc. Chem. Res. 2015, 48, 1687-1695; e) R. H. Morris, Acc. Chem. Res. 2015, 48, 1494 1502; f) R. Arevalo, P. J. Chirik, J. Am. Chem. Soc. 2019, 141, 91069123; g) C. S. G. Seo, R. H. Morris, Organometallics. 2019, 38, 47-65.

[10] a) S. Monfette, Z. R. Turner, S. P. Semproni, P. J. Chirik, J. Am. Chem. Soc. 2012, 134, 4561-4564; b) M. R. Friedfeld, M. Shevlin, J. M. Hoyt, S. W. Krska, M. T. Tudge, P. J. Chirik, Science. 2013, 342, 1076; c) J. Chen, C. Chen, C. Ji, Z. Lu, Org. Lett. 2016, 18, 1594-1597; d) J. Guo, B. Cheng X. Shen, Z. Lu, J. Am. Chem. Soc. 2017, 139, 15316-15319; e) J. Guo, X. Shen, Z. Lu, Angew. Chem. Int. Ed. 2017, 56, 615-618; f) M. R. Friedfeld, H. Zhong, R. T. Ruck, M. Shevlin, P. J. Chirik, Science. 2018, 360,$888 ;$ g) A. Mukherjee, D. Milstein, ACS Catal. 2018, 8, 1143511469; h) W. Ai, R. Zhong, X. Liu, Q. Liu, Chem. Rev. 2019, 119, 2876 2953; i) Y. Hu, Z. Zhang, J. Zhang, Y. Liu, I. D. Gridnev, W. Zhang, Angew.Chem. Int.Ed. 2019, 58, 15767-15771; j) X. Du, Y. Xiao, J.-M. Huang, Y. Zhang, Y.-N. Duan, H. Wang, C. Shi, G.-Q. Chen, X. Zhang, Nat. Commun. 2020, 11, 3239; k) H. Zhong, M. Shevlin, P. J. Chirik, J. Am. Chem. Soc. 2020, 142, 5272-5281.

[11] a) M. Shevlin, M. R. Friedfeld, H. Sheng, N. A. Pierson, J. M. Hoyt, L.-C. Campeau, P. J. Chirik, J. Am. Chem. Soc. 2016, 138, 3562-3569; b) W. Gao, H. Lv, T. Zhang, Y. Yang, L. W. Chung, Y.-D. Wu, X. Zhang, Chem Sci. 2017, 8, 6419-6422; c) Y.-Q. Guan, Z. Han, X. Li, C. You, X. Tan, H. Lv, X. Zhang, Chem. Sci. 2019, 10, 252-256; d) Y. Hu, J. Chen, B. Li, Z. Zhang, I. D. Gridnev, W. Zhang, Angew. Chem. Int. Ed. 2020, 59, 53715375 .

[12] Z. Zhang, N. A. Butt, M. Zhou, D. Liu, W. Zhang, Chin. J. Chem. 2018, 36, 443-454

[13] a) D. A. Valyaev, G. Lavigne, N. Lugan, Coord. Chem. Rev. 2016, 308, 191-235; b) G. A. Filonenko, R. van Putten, E. J. M. Hensen, E. A. Pidko Chem.Soc.Rev. 2018, 47, 1459-1483; c) F. Kallmeier, R. Kempe, Angew. Chem. Int. Ed. 2018, 57, 46-60; d) L. Alig, M. Fritz, S. Schneider, Chem. Rev. 2019, 119, 2681-2751.

[14] a) S. Elangovan, M. Garbe, H. Jiao, A. Spannenberg, K. Junge, M. Beller, Angew. Chem. Int. Ed. 2016, 55, 15364-15368; b) V. Papa, J. R. Cabrero-Antonino, E. Alberico, A. Spanneberg, K. Junge, H. Junge, M. Beller, Chem. Sci. 2017, 8, 3576-3585; c) M. Glatz, B. Stöger, D. Himmelbauer, L. F. Veiros, K. Kirchner, ACS Catal. 2018, 8, 4009-4016; d) A. Kaithal, M. Hölscher, W. Leitner, Angew. Chem. Int. Ed. 2018, 57, 13449-13453; e) A. Kumar, T. Janes, N. A. Espinosa-Jalapa, D. Milstein, Angew. Chem., Int. Ed. 2018, 57, 12076-12080; f) V. Zubar, Y. Lebedev,
L. M. Azofra, L. Cavallo, O. El-Sepelgy, M. Rueping, Angew. Chem. Int Ed. 2018, 57, 13439-13443; g) U. K. Das, A. Kumar, Y. Ben-David, M. A Iron, D. Milstein, J. Am. Chem. Soc. 2019, 141, 12962-12966; h) F. Freitag, T. Irrgang, R. Kempe, J. Am. Chem. Soc. 2019, 141, 11677 11685 ; i) V. Papa, Y. Cao, A. Spannenberg, K. Junge, M. Beller, Nat. Catal. 2020, 3, 135-142; j) Z. Wang, L. Chen, G. Mao, C. Wang Chin.Chem.Lett. 2020, 31, 1890-1894.

[15] S. Elangovan, C. Topf, S. Fischer, H. Jiao, A. Spannenberg, W Baumann, R. Ludwig, K. Junge, M. Beller, J. Am. Chem. Soc. 2016, 138, 8809-8814.

[16] a) M. Garbe, K. Junge, S. Walker, Z. Wei, H. Jiao, A. Spannenberg, S. Bachmann, M. Scalone, M. Beller, Angew. Chem. Int. Ed. 2017, 56 11237-11241; b) M. B. Widegren, G. J. Harkness, A. M. Z. Slawin, D. B. Cordes, M. L. Clarke, Angew. Chem.Int. Ed. 2017, 56, 5825-5828; c) L. Zhang, Y. Tang, Z. Han, K. Ding, Angew. Chem. Int. Ed. 2019, 58, 4973 4977; d) L. Zhang, Z. Wang, Z. Han, K. Ding, Angew. Chem. Int. Ed. 2020, 59, 15565-15569.

[17] a) A. Zirakzadeh, S. R. M. M. de Aguiar, B. Stöger, M. Widhalm, K Kirchner, ChemCatChem. 2017, 9, 1744-1748; b) R. van Putten, G. A Filonenko, A. Gonzalez de Castro, C. Liu, M. Weber, C. Müller, L. Lefort, E. Pidko, Organometallics. 2019, 38, 3187-3196; c) A. Passera, A Mezzetti, Angew. Chem. Int. Ed. 2020, 59, 187-191.

[18] a) S. Fu, Z. Shao, Y. Wang, Q. Liu, J. Am. Chem. Soc. 2017, 139, 11941 11948; b) Y. Wang, Z. Shao, K. Zhang, Q. Liu, Angew. Chem., Int. Ed. 2018, 57, 15143-15147; c) Y. Wang, L. Zhu, Z. Shao, G. Li, Y. Lan, Q. Liu, J. Am. Chem. Soc. 2019, 141, 17337-17349; d) Z. Shao, Y. Li, C. Liu, W. Ai, S.-P. Luo, Q. Liu, Nat. Commun. 2020, 11, 591.

[19] Y. He, Q. Fan, Chin. J. Org. Chem. 2019, 39, 3310-3311.

[20] F. Ling, H. Hou, J. Chen, S. Nian, X. Yi, Z. Wang, D. Song, W. Zhong, Org. Lett. 2019, 21, 3937-3941.

[21] V. I. Minkin, A. D. Garnovskii, J. Elguero, A. R. Katritzky, O. V. Denisko, in Advances in Heterocyclic Chemistry, Vol. 76 (Ed.: A. R. Katritzky), Academic Press, 2000, pp. 157-323.

[22] a) B. Zhao, Z. Han, K. Ding, Angew. Chem. Int. Ed. 2013, 52, 4744-4788; b) P. A. Dub, B. L. Scott, J. C. Gordon, J. Am. Chem. Soc. 2017, 139 1245-1260.

[23] J. Bálint, G. Egri, E. Fogassy, Z. Böcskei, K. Simon, A. Gajáry, A. Friesz, Tetrahedron Asymmetry. 1999, 10, 1079-1087.

[24] I. Jacquemond-Collet, F. Benoit-Vical, M. Valentin, A. Stanislas, E. Mallié I. Fourasté, Planta Med. 2002, 68, 68-69.

[25] B. Li, C. Xu, Y.-M. He, G.-J. Deng, Q.-H. Fan, Chin. J. Chem. 2018, 36, 1169-1173.

[26] T. Sammi, O. Silakari, M. Ravikumar, Chem Biol Drug Des. 2008, 71, 155-166.

[27] T. Asberom, H. S. Guzik, H. B. Josien, D. A. Pissarnitski, 2003, 58 pp. 
Table of Contents
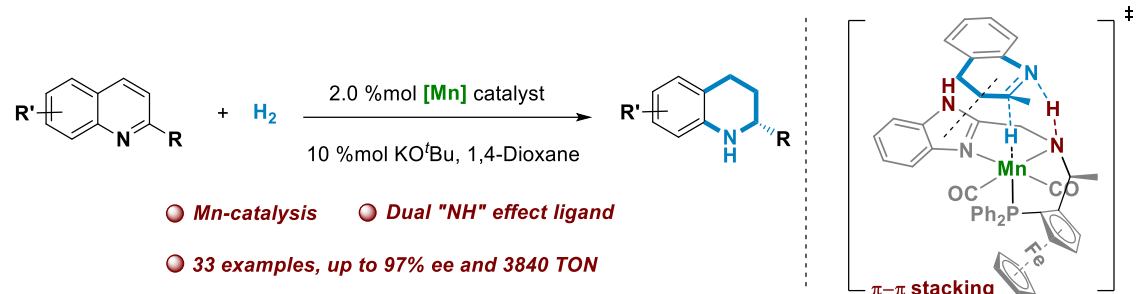

First example of non-noble metal-catalyzed asymmetric hydrogenation of aromatic N-heterocycles has been realized by using a welldefined chiral pincer manganese catalyst, with up to $97 \%$ ee and 3840 TON. 